\title{
Trágica História de um Criador de Valores*
}

\author{
Elysio de Carvalho**
}

\begin{abstract}
Resumo: Ensaio publicado no diário carioca Jornal do Commercio, em 1907. Neste texto, Elysio de Carvalho destaca a precedência do pensador em relação à sua obra, considerando que o lado mais atraente do estudo das obras de Nietzsche é o próprio filósofo, sua vida, suas vivências, dores e sofrimentos. É um dos primeiros autores a interpretar os textos de Nietzsche no Brasil.
\end{abstract}

Palavras-Chave: Nietzsche - vida - amor fati - filosofia - doença

Os gênios, seres segregados da humanidade, fora do sentir e do pensar comum, produtos de uma ignorada evolução étnica, forças da natureza cujo impulso a sociedade, institivamente, sempre desejosa da instabilidade, evita a todo transe, gravitam sobre si mesmos e ninguém conhece as leis desses desorbitados planetas que se tornam sóis. Frederico Nietzsche, uma das organizações cerebrais mais poderosas entre todas as que têm edificado o espírito humano, foi um desses desorbitados, e sua vida, nas circunstâncias em que se produziu, reveste-se de um caráter patético e terrível, foi uma beleza tão trágica, melancólica e pungente que dá a sua pessoa o valor de um símbolo. 0 maior filósofo dos tempos modernos,

* Publicado primeiro no Jornal do Commercio, no ano de 1907, depois reeditado no livro Bárbaros e Europeus. Rio de Janeiro: Garnier, 1909, p. 171-78.

** Elysio de Carvalho (1880-1925). Autor de livros de literatura, história, cultura em geral, anarquista e um dos fundadores da Universidade popular. 
o homem que teve a mais livre inteligência e mais fina sensibilidade de seu século, morre, mergulhado nas profundas trevas da loucura incurável, absoluta, como um facho luminoso apagado por violenta tempestade. Nas regiões translúcidas de um Alpes radioso e selvagem, os olhos glaucos cheios de sol e reflexos dos mares longínquos, os ouvidos repletos dos sussurros maviosos de um canto de lira que se nunca extingue, os lábios perfumados com o aroma das rosas, nessas alturas inacessíveis onde toda a animalidade se torna espiritual e toma asas, ele pairava quando a vertigem o lançou brutalmente por terra. $\mathrm{O}$ cérebro devorado pela demência, o espírito entorpecido, devia ficar assim durante um decênio, aterrorizado no meio das trevas da sua razão arruinada. Os lábios que tinham pronunciado palavras esplêndidas, admiráveis e augustas, só proferiam tolices. Prostrado, o semblante extinto, o olhar apagado para o exterior, sem sentir o que se desenrola dentro da sua alma, esquecido da vida e de tudo, imobilizado numa atitude macabra de esfinge, como que a pedir que se lhe arrancasse o segredo da sua loucura - "Mutter, ich bin dumm", murmurava ele, com uma persistência infantil, essa lamentação monótona que cortava o coração, vaga queixa com que parecia lembrar-se confusamente dele próprio, aquele que sonhou recriar a humanidade e dar-lhe uma moral que fosse um canto entusiasta à Vida Intensa. Nietzsche, que só viveu para pensar, a sua morte datando, portanto, do dia em que o encontraram inanimado na vizinhança do hotel que habitava em Turim, onde tinha ido ocultar sua orgulhosa majestade e gozar a solidão de seu espírito no meio de pessoas que lhe eram absolutamente estranhas, foi como o Prometeu das velhas fábulas pelágicas, que depois de escalar o Olimpo ficou vivendo a vida da dor eterna e da eterna edificação. A loucura foi o rochedo do Suplício, Cáucaso desse Titã dos tempos novos, a mandar para o mundo o seu clamor e a espantar a nossa consciência, no momento de morrer como um herói de Sófocles, ferido em seu orgulho e em sua genialidade. 
Nietzsche pertence a essa admirável dinastia de pensadores que vai de Kant, Goethe, Hegel, Fichte, Schelling, Schopenhauer, Feuerbach, Strauss, Stiner e Hartmann, arquétipos soberbos que encarnam sucessivamente as múltiplas aspirações da alma sonhadora da ambiciosa Germânia, e dominaram todo o pensamento filosófico do século que findou. Se Nietzsche foi um superior como intelectual, foi ainda grande como vítima do destino, um verdadeiro herói do pensamento: porque à dor opôs a majestade de seu gênio, mostrando que criar é a grande redenção do sofrimento. Outro não houve, sem esquecer Leopardi, que sofresse tanto, física e intelectualmente, e ninguém melhor do que ele tirou um tão magnífico partido da dor. A dor foi a sua musa inseparável: foi ela que o condenou à solidão, que lhe permitiu descer até o fundo perturbado, enfermo, esgotado da alma moderna, que lhe ensinou a grande alegria - a alegria de viver, a alegria de criar e a alegria de sofrer -, o riso supremo do vitorioso coroado de pâmpanos, rosa e beijos.... Assim, o que constituirá sempre o lado mais atraente do estudo das obras de Nietzsche é o próprio filósofo, são os sofrimentos, os martírios, as amarguras, as decepções, os desejos e as alegrias, as esperanças dessa vasta inteligência - "os seus dias de festa e os seus dias de luto -, são as enfermidades, as convalescenças e as curas dessa alma excepcional, que materializou as admiráveis visões numa língua misteriosa, imprevista e sugestiva. A propósito de Nietzsche, pode-se repetir aquele célebre paradoxo em que ele afirma que a doutrina de um pensador importa pouco, porque o filósofo pode enganar, a qualidade de sua alma valendo mais que todo sistema: "Há num filósofo o que nunca houve numa filosofia: quero dizer, a causa de muitos filósofos - o grande homem". Frederico Nietzsche, segundo a justa classificação do professor Kurt Breysig, é o protótipo mais acabado de um pensador de temperamento, expressão inventada para a filosofia subjetivista ou de confissão (Bekenntnissphilosophie), em oposição à filosofia de conhecimento (Erkenntnissphilosophie). "As minhas obras", escreve ele, "dizem unicamente das vitórias sobre mim mesmo (mihi ipsi scripsi), e os meus livros são os mais vividos". 
Nietzsche, na verdade, foi um filósofo que caminhou "por cem almas e por cem berços, e por cem dores de parto". Toda a sua obra deve ser considerada como a mais épica, a mais singular, a mais imperativa e a mais notável autobiografia que ainda se escreveu: é a canção de gestos da Vida celebrando a beleza, a força é a sua ascensão indefinida.

De antemão, tinha Nietzsche se comprometido a aceitar seu destino, qualquer que ele fosse. No dizer dele, é uma loucura querer julgar a Vida. $\mathrm{O}$ homem é um ser condenado à vida $\mathrm{e}$, segundo sonha, condenado a viver um sem-número de vezes a mesma vida e a reviver ainda, eternamente. Não podendo fugir a esta fatalidade absoluta, só nos resta uma atitude digna, nobre, heroica: considerar a vida como um espetáculo magnífico, uma incomparável aventura, um brinco maravilhoso, suportá-la com todas as suas fealdades, incoerências e quebrantos, amá-la, enfim, tal qual é e como poderia ser por nossa ação, como se ama uma amante que nos engana, tortura e martiriza, mas que, no entanto, nos seduz pelo imprevisto que suas carícias nos proporcionam. "Aimer, c'est le grand point", diz Musset, "qu’importe la mâ̂tresse". A vida só é má para aqueles que pensam encontrar depois da morte uma recompensa aos sofrimentos na terra, e ignoram que um fragmento de beleza basta muitas vezes para iluminar uma existência inteira, tornar a vida suportável.

Não sei se a vida é por si mesma boa ou má. Nada, com efeito, é mais vão do que essa eterna controvérsia entre otimistas e pessimistas; e isso por uma razão de grande força, e é que no mundo ninguém possui qualidades para julgar o que vale a vida: os vivos não o podem, porque são partes no debate e até são objetos do litígio, e os mortos não o podem ainda... porque são mortos. $\mathrm{O}$ que vale a vida ninguém pode, portanto, dizer. Estou certo de que ignorei para sempre se teria sido melhor para

118 | Cad. Nietzsche, São Paulo, v.36 n.1, p. 115-125, 2015. 
mim ser ou não ser. No entanto, uma vez que vivo, quero que a vida seja tão exuberante, tão emocionante, tão tropical quanto possível, e isso em mim e fora de mim. Direi, portanto - sim a tudo que torna a vida mais bela, mais digna de ser vivida, mais intensa. Se me demonstrarem que o erro e a ilusão podem servir ao desenvolvimento da vida, eu direi - sim ao erro e à ilusão; se me provarem que os instintos qualificados maus pela moral vigente - por exemplo, a dureza, a crueldade, a astúcia, vitalidade do homem, direi - sim - ao mal e ao pecado; se me for demonstrado que o sofrimento concorre, tanto como o prazer, para a educação do gênero humano, eu direi - sim - ao sofrimento. Ao contrário, direi - não - a tudo o que diminui a vitalidade da planta humana. E se descubro que a verdade, a virtude, o bem, numa palavra, todos os valores respeitados até o presente pelos homens são prejudiciais à vida, direi - não - à ciência e à moral.

Toda a realidade fenomenal se resume nesta constatação: $a$ vida existe. Ora, desde o momento que a vida é, que esse fato nos é dado e que o contrário não nos é dado, o pessimismo de Schopenhauer é uma aspiração vã, uma revolta inútil e pueril contra o inevitável. A Vida, inexplicável do ponto de vista da razão, não tem necessidade de ser justificada, só pode ser justificada como um fenômeno estético. Valendo tão-só como representação, o que se deve exigir é que esse espetáculo seja belo, a beleza sendo, no espírito, em face do fenomenalismo universal, o único conceito real, a única realidade que nos é conhecida de uma maneira relativa, ela tendo ainda o poder de nos pôr em relação com o universo e fazer surgir para nós o mundo como representação. A arte é a surpresa explicação da Vida, a beleza é redentora da Dor, e só ela é moralidade perfeita.

Poeta, vidente, pensador, investigador apaixonado e intrépido, psicólogo sutil e profundo, grande entusiasta da Vida e da Beleza, Nietzsche procurou saber como os povos de cultura superior 
resolveram antes de nós o problema da existência, ou, para falar sua linguagem, como suportaram a dor de viver. Os gregos, por exemplo, cuja alma não era tão serena como erradamente supunham Winckelmann e Goethe, e possuindo todos os elementos de uma filosofia pessimista, como os combates de Titãs que figuram na origem de sua história, o inexorável Destino que pesava sobre toda a vida humana, o abutre que devora as entranhas de Prometeu, porque ele era "amigo dos homens", a sorte terrível do sábio Édipo, incestuoso e parricida, a maldição que perseguia todos os membros da família dos Atrides e que arrastou Orestes ao matricídio, sentindo, em suma, o horror e a dor de viver, escaparam, no entanto, ao desespero. Nesse livro soberbo que é a Origem $d a$ Tragédia, e com o qual veio inaugurar uma nova, uma preciosa maneira de ler, interpretar e versar os gregos, diz como a psicologia do estado orgiástico, interpretada como um sentimento de vida e de força transbordante, em que a dor mesma é sentida como se fosse prazer, mostrou-lhe o caminho que conduzia à noção do trágico. A alma trágica não se quer libertar do terror e da piedade - não, quer, acima da piedade e do terror, fazer-se, ela própria, a alegria eterna do ente que se transforma, do ente que vai viver, essa alegria que compreende também o gozo do aniquilamento. Nietzsche encontra, para livrar o homem do pessimismo, na cultura grega, a sabedoria trágica, nascida do conúbio da visão apolínea e do espírito dionisiano, e graças à qual os helenos do período homérico afirmaram a vida nos seus problemas mais árduos e mais tremendos, a sua vontade de viver, exaltando os seres na consciência de sua fecundidade irresponsável em face da destruição dos mais belos tipos da humanidade. Apolo, o deus que interpreta os sonhos, e Dionísio, o deus que preside às orgias da imaginação, exprimem as duas faces da inspiração poética e personificam os polos opostos do gênio grego. O homem, possuindo um tom de criação, cultivado, refinado, desenvolvido e perfeito (visão apolínea), e cheio de confiança em si próprio, deve, mesmo em prejuízo de outrem e sem se importar com os preconceitos considerados como princípios fundamentais pelo 
maior número, viver a vida segundo o máximo de energia, tomar sua parte de beleza na terra - "sonhar" sua vida, porque o essencial do ato estético é a criação de uma "imagem" de beleza cujos elementos são tomados do mundo exterior, mas o conjunto devendo ultrapassá-lo. É no sonho que esplêndidas imagens dos deuses se manifestam pela primeira vez na alma do homem, é no sonho que o grande escultor percebe as proporções divinas das criaturas super-humanas, é no sonho também que o poeta heleno concebe os mistérios de sua arte criadora. A visão apolínea tem ainda o poder de transformar a dor em sereno gozo pela contemplação do mundo como uma criação maravilhosa do demiurgo. O homem, não sendo, porém, um ser isolado na natureza e na sociedade, sua vontade dependendo da vontade universal que é eterna e infinita, ele, nos momentos de êxtase (estado dionisiano), sentirá sua alma estender-se pela natureza inteira, a fim de que se comunique com o poder eterno que percebe sob o influxo perpétuo dos fenômenos. Numa palavra, o homem deve concentrar-se e dispersar-se, alternativamente, depois de um tipo de beleza, conforme a sua natureza primeira, desembaraçado de todo entrave superior, à força de vontade, aos tipos fornecidos pelo meio ambiente. Assim, graças a essas duas ilusões sedutoras, a ilusão dionisiana e a ilusão apolínea, com as quais os gregos conseguiram, no meio da universal transformação e do universal sofrimento, triunfar do pessimismo que condena a vida como indigna de ser estimada, o homem pode aceitar o mundo, não só como necessário mas como desejável, tal qual é, sem desfalque e sem exceção, com as mesmas coisas e o mesmo ilogismo do encadeamento. Defendido por este forte estimulante contra todo pessimismo, Nietzsche aceita a vida que lhe é imposta, os sofrimentos e as inquietações de seu excepcional temperamento, pratica essa atitude trágica muito cara aos gregos, é dionisiano em face da existência ilógica, múltipla e sem fim. Destarte, ele quer a Vida em toda a sua plenitude, sem preferir a alegria à dor, visto a embriaguez da vida ser igual na alegria como na dor, sem preferir o que se chama virtude ao que se chama crime, visto a potência de 
vida ser igual tanto no crime como na virtude. Abatido, atormentado por dores morais e físicas, mas não admitindo que o sofrimento pudesse ser um bem, sugerindo que o pessimismo é um sintoma de miséria fisiológica e de impotência intelectual, e, ainda mais, sabendo que a felicidade consiste precisamente no querer, consegue por várias vezes que seu corpo enfermo recupere a saúde.

De novo descubro a vida - escrevia ele em 1880 -, volto à posse da minha personalidade, saboreio todas as boas coisas, mesmo as pequenas, como outros poderão muito dificilmente saboreá-las. Fiz de minha vontade de curar, de viver, minha filosofia. Que se tome nota, com efeito: os anos em que minha vitalidade descia a seu mínimo formam aqueles em que cessei de ser pessimista: o instinto de conservação interdiz-me uma filosofia da indigência e da pusilanimidade. O filósofo não tem o direito de ser pessimista.

Por uma curiosa inversão do schopenhaurismo, depois de muitos anos de padecimentos atrozes e de ter debalde ensaiado um sem-número de narcóticos, volta ao gozo sereno e inaudito da liberdade, começa a sonhar dias melhores e tem o pressentimento dos mundos novos que se abriram ante a sua visão mental. Admirável vitória da vontade sobre a própria alma, maravilhosa volta a si mesmo, que lhe faz dizer, quando termina La Gaya Scienza:

Este livro não é senão as saturnais de um espírito que resiste pacientemente a uma terrível e longa pressa - pacientemente, severamente, friamente, sem submeter-se, mas sem esperança, e que hoje, de súbito, é assaltado pela esperança, pela esperança da cura, pela ebriedade da cura. É que todo este livro não é senão festa depois das privações e das fraquezas, é a rejubilação das forças renascentes, a nova fé no amanhã e no depois de amanhã, sentimento súbito e o pressentimento do porvir, das aventuras próximas e dos mares novamente abertos, dos fins permitidos outra vez e nos quais é de novo permitido crer. 
Nietzsche entoando um hino entusiasta à Vida depois de uma penosa enfermidade em que se viu perto da morte ou da loucura, lembra Sófocles louvando Dionísio, o deus do vinho e da alegria, depois dos horrores de Édipo Rei. A atitude do visionário de Engadina sobrepuja, em beleza e em força, a sabedoria gélida dos estóicos: Epíteto e Marco Aurélio reprovariam uma tal exuberância: e isto porque eles não queriam viver, aspiravam à grande paz do túmulo onde se extinguem todas as ilusões dolorosas e todos os vãos tormentos. Nisto, nessa adoração quand même da existência, reside a parte mais fecunda de sua filosofia, a qual estabelece como lei primeira o amor fati, fórmula suprema que foi o seu evangelho, o seu grande amor, e é a única que julga capaz para a grandeza de um homem: amar seu destino, amar sua fatalidade, amar o que é, amar o que há de ser; não querer mudar nenhum fato, no passado, no futuro, e considerá-lo como existindo eternamente; não apenas suportar a necessidade, menos ainda dissimulá-la - pois todo idealismo é uma mentira em face da necessidade -, mas amá-la. Tal foi maneira dessa alma nobre.

*

Nietzsche é um espetáculo magnífico, e sem essa gaya scienza a que atribui o poder de revelação dos segredos da história da civilização e da cultura humana, não teria podido triunfar dos seus sofrimentos. Foi sobrepujando a dor que ele chegou a essa serenidade olímpica que o coloca como que acima da vida. De fato, sofreu sem fraquezas e sem atitudes trágicas e teatrais, sem desesperos, sofreu pacientemente, voluntariamente e heroicamente sabendo de antemão que seria um vencido, preocupado tão-só em tirar, enquanto filósofo e psicológico, o melhor partido das suas grandes dores e dos seus inevitáveis infortúnios. Ele confessa que graças aos seus sofrimentos físicos atravessou "estados sublimes" que lhe fizeram conhecer alguma coisa que não pode compreender o homem não tendo nunca experimentado essa espera da morte que 
o trouxe sempre em sobressalto. Desses "estados sublimes" que se vangloria de ter sucessivamente conhecido, Nietzsche dá-nos uma pintura minuciosa no aforismo autobiógrafo 114 da Aurora, escrito para mostrar que a doença não é sem valor para o conhecimento da Vida, e confessa, alhures, que deve mais à sua doença que à própria saúde:

Indubitavelmente - diz ele -, devo mais à minha doença que à minha saúde: devo-lhe a saúde superior que fortifica o homem no meio de tudo que não mata; devo-lhe a minha filosofia. $\mathrm{O}$ grande sofrimento é o supremo libertador do espírito, é a grande educadora da humanidade, é o grande mestre a que o homem deve os seus mais belos títulos de nobreza. Só esse sofrimento, lento e prolongado, que nos consome, por assim dizer, como um fogo de verde lenho que arde dificilmente, obriga-nos, a nós outros filósofos, a descer às profundezas de nossa alma e a rejeitar para bem longe de nós tudo que é clemente, pacífico, indulgente, tenro e medíocre, isto é, todos esses sentimentos nos quais críamos até então residir nossa humanidade.

Sabendo que toda filosofia é não um conjunto de verdades abstratas e impessoais, mas a objetivação de um temperamento, a expressão de uma fisiologia, uma confissão involuntária e inconsciente de seu autor, ou melhor, que a vida intelectual é uma tradução da vida física, foi levado naturalmente a estudar com um interesse particular o problema das relações da saúde com a filosofia, fazendo nesse sentido descobertas admiráveis. $\mathrm{O}$ destino tendo-lhe enviado um conhecimento supremo, uma experiência rara, um novo método para medir tudo o que existe, não deixou escapar essa fortuna, e, com a energia necessária, com grande sangue-frio e a objetividade do sábio que examina um caso curioso, soube ver em seu estado precário de saúde uma experiência psicológica de um alcance excepcional. Nietzsche, para conhecer quais os efeitos da depressão física sobre o espírito do pensador, teve a grande vantagem de ter atravessado diversos estados de saúde e, portanto, 
vivido um maior número de filosofias. E quando, doente, se lhe deparou, diz ele, um país desconhecido, cujas fronteiras ainda não tinham sido vistas por ninguém, conquista, arriscando a própria experiência, um mundo tão rico de coisas belas, estranhas, duvidosas e divinas, que a sua curiosidade e sua sede de possuir, saindo dos gonzos, transbordaram ruindo através da região das inatualidades.

\begin{abstract}
Essay published in the daily Jornal do Commercio, in 1907, in Rio de Janeiro. In this text, Elysio de Carvalho highlights the thinker precedence over his work, considering that the most attractive side of the study of the works of Nietzsche is the philosopher himself, his life, his experiences, aches and suffering. It is one of the first authors to interpret Nietzsche's texts in Brazil.
\end{abstract}

Keywords: Nietzsche - life - love fate - philosophy - disease 
